\title{
Publisher Correction: Human CD45 is an F-component-specific receptor for the staphylococcal toxin Panton-Valentine leukocidin
}

Angelino T. Tromp, Michiel Van Gent (D), Pauline Abrial, Amandine Martin, Joris P. Jansen, Carla J. C. De Haas, Kok P. M. Van Kessel, Bart W. Bardoel D, Elisabeth Kruse, Emilie Bourdonnay, Michael Boettcher, Michael T. McManus, Christopher J. Day, Michael P. Jennings (D), Gérard Lina, François Vandenesch D, Jos A. G. Van Strijp, Robert Jan Lebbink, Pieter-Jan A. Haas, Thomas Henry (iD and András N. Spaan (i)

Correction to: Nature Microbiology https://doi.org/10.1038/s41564-018-0159-x, published online 7 May 2018.

In the version of this Article originally published, the name of author Robert Jan Lebbink was coded wrongly, resulting in it being incorrect when exported to citation databases. This has now been corrected, though no visible changes will be apparent.

Published online: 3 September 2018

https://doi.org/10.1038/s41564-018-0247-y 